\title{
КОНЦЕПТУАЛЬНІ ОСНОВИ ФІЗИЧНОЇ РЕАБІЛІТАЦІї ХВОРИХ НА ХРОНІЧНЕ ОБСТРУКТИВНЕ ЗАХВОРЮВАННЯ ЛЕГЕНЬ
}

\author{
○І. М. Григус ${ }^{1}$, П. С. Подоляка', Т. В. Гамма', І. С. Подолянчук', \\ ${ }^{1}$ Навчально-науковий інститут охорони здоров'я Національного університету \\ водного господарства та природокористування \\ ${ }^{2}$ Кременецька обласна гуманітарно-педагогічна академія імені Тараса Шевченка
} Л. О. Зарічанська', Т. В. Кучер²

РЕЗЮМЕ. Хронічне обструктивне захворювання легень (ХОЗЛ) на сьогодні $є$ однією з найпоширеніших форм патології, що призводить до високої захворюваності населення та смертності пацієнтів. Питання фізичної реабілітації хворих на ХОЗЛ на сучасному етапі стоїть досить гостро. Це пов'язано з тим, що саме у таких пацієнтів спостерігається найбільше зниження пристосування організму до фізичного навантаження, а ефект від лікарської терапії може бути значно посилений шляхом упровадження реабілітаційних програм.

Мета - науково обґрунтувати концептуальні основи фізичної реабілітації хворих на хронічне обструктивне захворювання легень.

Результати. Концепцію фізичної реабілітації хворих на ХОЗЛ слід здійснювати з урахуванням низки передумов: соціально-педагогічних, біологічних та особистісних. Концепція фізичної реабілітації хворих на ХОЗЛ включає теоретичну складову, розроблену з урахуванням передумов здійснення реабілітаційного процесу, до якої віднесені концептуальні підходи і основи, а також практичну складову у вигляді технології фізичної реабілітації.

Концепція використовує концептуальні підходи: системно-історичний, системно-діяльнісний, системнофункціональний, системно-цільовий, системно-структурний, системно-ресурсний, системно-комунікаційний та системно-інтеграційний.

У концепції всі елементи, що об'єднані фундаментальним задумом і провідною ідеєю, являють собою сукупність поглядів, а ії концептуальна основа - це мета, завдання, принципи й методи, які забезпечують розуміння ії̈ системних механізмів, алгоритм побудови та функціонування. Значна увага приділялася особливостям супутніх порушень, що впливають на загальну картину фізичної реабілітації. Організаційні основи базувалися на програмах фізичної реабілітації, що враховували всі індивідуальні особливості хворих.

Висновки. Запропонована цілісна концепція фізичної реабілітації ґрунтувалася на використанні комплексного лікувального і педагогічного підходу, мала індивідуальну спрямованість з врахуванням рівня рухових можливостей, якості життя, фізичної працездатності хворих, функціонального стану кардіореспіраторної системи, функції зовнішнього дихання.

КлючОВІ СлОВА: хронічне обструктивне захворювання легень; хворі; концепція; фізична реабілітація.

Вступ. На сьогодні ХОЗЛ $є$ однією з найпоширеніших форм патології, що призводить до високої захворюваності населення та смертності паці$\epsilon$ нтів. Економічні збитки, пов'язані з лікуванням загострень захворювання, відшкодуванням за втрату працездатності, інвалідизацію постраждалих внаслідок професійних захворювань постійно зростають в усіх країнах світу. Незважаючи на те, що медикаментозна базисна терапія згідно з Міжнародним та Національним консенсусами чітко регламентована, багато питань, пов'язаних з профілактикою, реабілітацією та оздоровленням хворих на ХОЗЛ, залишаються недостатньо вивченими $[2,9,12]$.

Питання фізичної реабілітації хворих на ХОЗЛ на сучасному етапі досить актуальне. Це пов'язано з тим, що саме у таких пацієнтів найбільше знижується пристосування організму до фізичного навантаження, а ефект від лікарської терапії може бути значно посилений шляхом упровадження реабілітаційних програм. Проте хронічний характер патології та наростаюча задишка, переважно літній вік, зниження м'язової маси і сили призводять до обмеження функціональних можливостей та зумовлюють необхідність постійної терапії, погіршують якість життя $[4,6,13]$.

3 огляду на вищевикладене, погіршення сучасного стану проблеми з ХОЗЛ і недостатню ефективність запропонованих програм фізичної реабілітації, виникає необхідність наукової розробки і впровадження концепції фізичної реабілітації хворих на ХОЗЛ.

Результати й обговорення. Згідно з висновком Американського торакального товариства i Європейського респіраторного товариства, реабілітація повинна базуватися на даних доказової медицини, проводитися мультидисциплінарною командою, включати лікувальні заходи для всіх хворихзхронічними респіраторнимизахворюваннями і зниженою повсякденною активністю $[10,14]$.

Малявін А. Г. зі співавторами застерігають від протиставлення лікування і реабілітації, які повинні бути тісно пов'язані між собою і взаємно доповнюваними. Вони наголошують, що відновне ліку- 
Огляди літератури, оригінальні дослідження, погляд на проблему, випадок з практики, короткі повідомлення вання - це невід'ємна частина реабілітації, яка повинна починатися з найраніших стадій травми або хвороби $[7,8]$.

У багатьох матеріалах відзначається однаковість цілей проведеної фізичної реабілітації. До них відносять поліпшення переносимості фізичного навантаження, зменшення задишки в повсякденному житті, полегшення клінічних симптомів хвороби, запобігання загостренням, поліпшення якості життя $[1,2,5]$.

Фізичні вправи $є$ найдоступнішим засобом поліпшення стану м'язів при ХОЗЛ. Проведення фізичних тренувань показане всім хворим зі зниженою переносимістю фізичних навантажень, задишкою, втомою при навантаженні й обмеженням повсякденної активності. Більшість досліджень, присвячених цій проблемі, показали, що

позитивні результати фізичної реабілітації не залежать від віку, статі, анамнезу куріння, легеневої функції. Ряд науковців продемонстрували, що результати, що досягаються в програмах фізичної реабілітації хворими на ХОЗЛ різного ступеня тяжкості, можна порівняти $[3,9,12]$.

Розробку концепції фізичної реабілітації хворих на ХОЗЛ слід здійснювати з урахуванням низки передумов: соціально-педагогічних, біологічних, особистісних (рис. 1).

Основою соціально-педагогічних передумов $\epsilon$ недостатньо ефективна організація фізичної реабілітації хворих з патологіями дихальної системи на лікарняному, післялікарняному та санаторно-курортному етапах лікування; необхідність навчання щодо самоведення. Реабілітація найчастіше проводиться при клінічній стабільності хво-

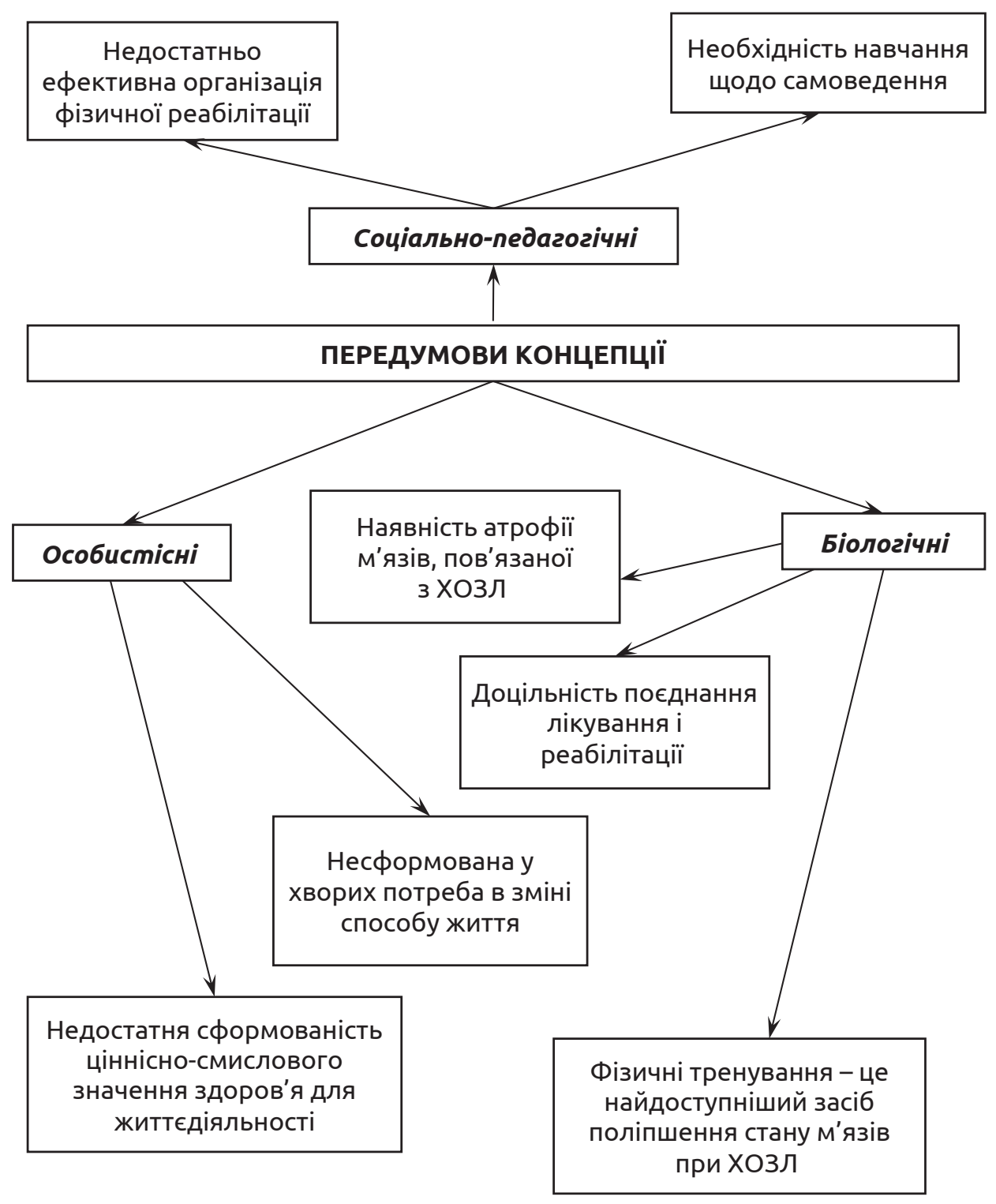

Рис. 1. Передумови розробки концепції фізичної реабілітації хворих на ХОЗЛ. 
Огляди літератури, оригінальні дослідження, погляд на проблему, випадок з практики, короткі повідомлення рого, а не в період загострення. Проте, призначення фізичної реабілітації під час або відразу після загострення має раціональну основу.

Необхідність єдності підходів до основних положень фізичної реабілітації, поява наукової доказової бази, просування вперед в розумінні патофізіології хронічних захворювань органів дихання і розширення показань до використання відновного лікування привели до створення «Об'єднаної угоди з легеневої реабілітації», прийнятої Радою директорів Американського торакального товариства (ATS ) і виконавчим комітетом ERS в 2005 році [10].

Підставою біологічних передумов $€$ наявність атрофії м'язів, пов'язаної з ХОЗЛ; доцільність поєднання лікування і реабілітації; фізичні тренування - це найдоступніший спосіб поліпшення стану м'язів при ХОЗЛ.

Особистісні передумови - це несформована у хворих потреба у веденні здорового способу життя; недостатня сформованість ціннісно-смислового значення здоров'я для життєдіяльності.

Основною ланкою успішного впровадження фізичної реабілітації $\epsilon$ свідоме дотримання хворими на ХОЗЛ здорового способу життя.

Існує необхідність створення стандартів проведення фізичної реабілітації з виробленням оптимального комплексу заходів і тривалості їх проведення. Крім цього, необхідно розробляти способи збереження ефектів фізичної реабілітації, особливо за рахунок вдосконалення довготривалого «самоведення» і прихильності пацієнтів до фізичних тренувань у домашніх умовах [11].

На підставі аналізу передумов, що впливають на характер і спрямованість процесу фізичної реабілітації хворих на ХОЗЛ, висновку Американського торакального товариства і Європейського респіраторного товариства, результатів власних досліджень, рекомендується наступна концепція фізичної реабілітації хворих на ХОЗЛ. Розроблена концепція (рис. 2), виходячи з мети, ґрунтується на дидактичних принципах і принципах фізичної реабілітації, на системних, концептуальних підходах, організаційних, методичних і концептуальних основах процесу відновлення здоров'я хворих на ХОЗЛ.

Авторську концепцію деталізовано в положеннях, які відображені в низці робіт (І. М. Григус, 2011; О. Я. Андрійчук, 2013; О. Б Лазарєва, 2013; О. В. Андрєєва, 2014; С. М. Футорний, 2015, Н. Є. Нестерчук, 2015; А. І. Альошина, 2016; І. О. Жарова, 2016; О. К. Ніканоров, 2016), а саме таких, як актуальність, прогнозованість, раціональність, цілісність, контрольованість. Під час розробки концепції фізичної реабілітації хворих на ХОЗЛ спиралися на наступні концептуальні підходи.

Концепція фізичної реабілітації хворих на ХОЗЛ включає теоретичну складову, розроблену з урахуванням передумов здійснення реабілітаційного процесу, до якої віднесені концептуальні підходи і основи, а також практичну складову у вигляді технології фізичної реабілітації.

Концепція використовує концептуальні підходи:

- системно-історичний - дозволив з'ясувати підходи до системи фізичної реабілітації пульмонологічних хворих;

- системно-діяльнісний - дозволив активно залучити до процесу фізичної реабілітації хворих на ХОЗЛ, навчаючи вибирати, оцінювати, програмувати і конструювати свою діяльність, змінити спосіб життя, навчитися враховувати потреби організму, саморозвиватися для досягнення найвищих можливих результатів у подоланні хвороби;

- системно-функціональний - дозволив виявити функціональний стан систем організму, насамперед дихальної та серцево-судинної систем, i якість життя хворих на ХОЗЛ;

- системно-цільовий - дозволив визначити і обґрунтувати мету фізичної реабілітації хворих на ХОЗЛ;

- системно-структурний - дозволив вивчити різнобічний вплив обструктивного синдрому на різні системи організму та функціональний стан;

- системно-ресурсний - передбачав розв'язання таких завдань, як формування та підвищення рівня здоров'я, розробка комплексу різноманітних засобів, методів і організаційних форм процесу фізичної реабілітації хворих на ХОЗЛ та набуття ними необхідних теоретичних знань;

- системно-комунікаційний - дозволив забезпечити зв'язок між відновним процесом і зовнішнім середовищем з залученням у процес реабілітації найближчого до пацієнта з ХОЗЛ соціального оточення;

- системно-інтеграційний - дозволив виявити найефективніші й найраціональніші засоби, що склали систему фізичної реабілітації, поєднуючи традиційні та інноваційні методи при функціональних порушеннях.

У концепції всі елементи, що о6'єднані фундаментальним задумом і провідною ідеєю, являють собою сукупність поглядів, а її концептуальна основа - це мета, завдання, принципи й методи, які забезпечують розуміння її системних механізмів, алгоритм побудови та функціонування.

Значна увага приділялася особливостям супутніх порушень, що впливають на загальну картину фізичної реабілітації. Організаційні основи базувалися на програмах фізичної реабілітації, що враховували всі індивідуальні особливості 
Огляди літератури, оригінальні дослідження, погляд на проблему, випадок з практики, короткі повідомлення

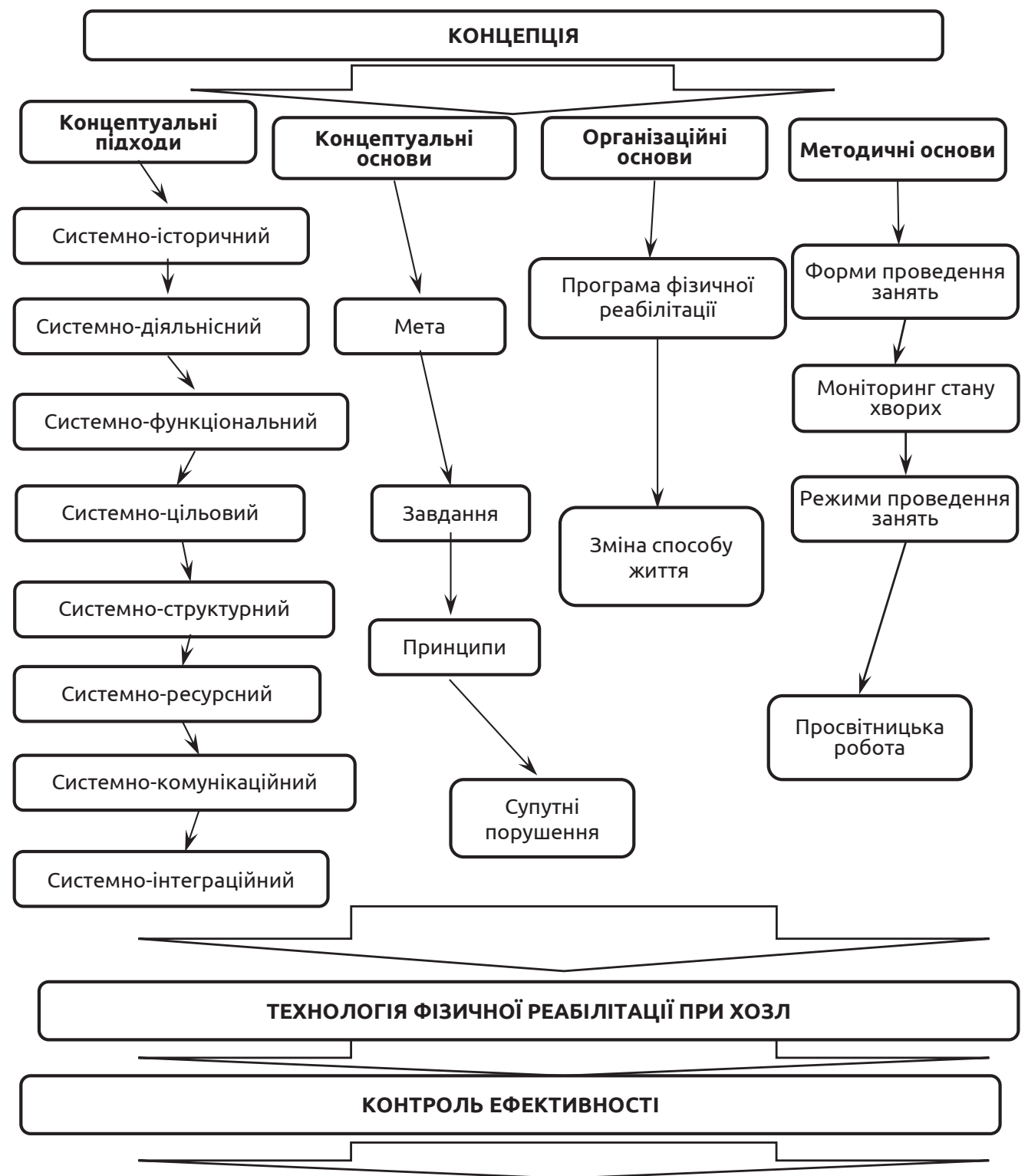

Результат: зняття бронхообструктивного синдрому, зниження проявів дихальної та серцевої недостатності, частоти загострень; подовження періоду ремісії; повернення до повноцінної трудової і побутової діяльності; підвищення якості життя

Рис. 2. Блок-схема концепції фізичної реабілітації хворих на ХОЗЛ.

хворих. Обов'язковою умовою було дотримання здорового способу життя.

Висновки. Фізична реабілітація повинна посідати провідне місце в комплексному лікуванні пацієнтів із ХОЗЛ. Впроваджена в щоденне лікування хворих реабілітація дозволить зменшити прояви хвороби, оптимізувати функціональний статус хворого і знизити вартість лікування за рахунок стабілізації або зменшення системних проявів хвороби. Необхідністю проведення й загальними завданнями фізичної реабілітації $\epsilon$ досягнення регресії зворотних і стабілізації незворот- них змін у бронхах, відновлення й покращення функції зовнішнього дихання та фізичної працездатності. Реалізація цих завдань може відрізнятися залежно від нозологічної форми, особливостей і характеру перебігу ХОЗЛ, індивідуальних особливостей пацієнта, форми й ступеня ураження дихальної системи.

Запропонована цілісна концепція фізичної реабілітації ґрунтувалася на використанні комплексного лікувального і педагогічного підходу, мала індивідуальну спрямованість, враховувалися рівень рухових можливостей, якість життя, фі- 
Огляди літератури, оригінальні дослідження, погляд на проблему, випадок з практики, короткі повідомлення зична працездатність хворих, функціональний стан кардіореспіраторної системи, функція зовнішнього дихання.

Перспективи подальших досліджень вбачаємо у клінічному вивченні ефективності застосування запропонованої концепції фізичної реабілітації хворих на ХОЗЛ різного ступеня тяжкості.

\section{ЛІТЕРАТУРА}

1. Григус І. М. Відновлення фізичної працездатності хворих на хронічне обструктивне захворювання легень у процесі фізичної реабілітації / І. М. Григус, М. І. Майструк // Науковий Часопис НПУ імені М. П. Драгоманова: серія 15 "Науково-педагогічні проблеми фізичної культури (фізична культура і спорт)". - 2018. № (98). - С. 46-51.

2. Григус І. М. Зміни функції зовнішнього дихання у хворих на хронічне обструктивне захворювання легень при застосуванні фізичної реабілітації / І. М. Григус, М. І. Майструк // Науковий Часопис НПУ імені М. П. Драгоманова: серія 15 "Науково-педагогічні проблеми фізичної культури (фізична культура і спорт)". 2018. - № 1 (95). - С. 15-19.

3. Вплив проведеної фізичної реабілітації на якість життя хворих на ХОЗЛ / І. М. Григус, Н. Є. Нестерчук, А. О. Ногас [та ін.] // Здобутки клінічної і експериментальної медицини. - 2018. - № 4. - С. 70-74.

4. Григус І. Аналіз фізичної активності хворих на хронічне обструктивне захворювання легень при застосуванні фізичної реабілітації / І. Григус, М. Майструк // Фізична активність, здоров'я, спорт. - 2017. № 3 (29). - С. 68-77.

5. Григус І., Майструк М. Зміни функції зовнішнього дихання у хворих на хронічне обструктивне захворювання легень 1 ступеня тяжкості у процесі фізичної реабілітації / І. Григус, М. Майструк // Вісник Прикарпатського університету. Серія: Фізична культура. - 2018. Вип. 30. - С. 19-27.

6. Григус І. Оцінка ефективності фізичної реабілітації хворих на хронічне обструктивне захворювання легень помірного ступеня тяжкості / І. Григус, М. Майструк // Молодіжний науковий вісник Східноєвропейського національного університету імені Лесі Українки.

Фізичне виховання і спорт : журнал / уклад. А. В. Цьось, А. І. Альошина. Луцьк : Східноєвроп. нац. ун-т ім. Лесі Українки. - 2018. - Вип. 29. - С. 89-96.

7. Малявин А. Г. Респираторная медицинская реабилитация : практическое руководство для врачей / А. Г. Малявин. - М.: Практическая медицина, 2006. -416.

8. Малявин А. Г. Реабилитация при заболеваниях органов дыхания / А. Г. Малявин, В. А. Епифанов, И. И. Глазкова. - М. : ГЭОТАР-Медиа, 2010. - 352 с.

9. Пономаренко Г. Н. Синдромно-патогенетический подход - стратегия развития физиотерапии в XXI веке / Г. Н. Пономаренко // Мед. реабилитация, курортология, физиотерапия. - 2000. - № 1 (21). - С. 7-9.

10. Стандарты по диагностике и лечению больных ХОЗЛ (ATS/ERS, пересмотр 2004 г.) ; пер. с англ.; под ред. А. Г. Чучалина. - М. : Атмосфера, 2005. - 96 с.

11. Home-based pulmonary rehabilitation program: effect on exercise tolerance and quality of life in chronic obstructive pulmonary disease patients / M. Ghanem, E. A. Elaal, M. Mehany, K. Tolba // Annals of Thoracic Medicine. - 2010. - Vol. 5 (1). - P. 18-25.

12. Grygus I. Effect of physical therapy on respiratory function in patients with chronic obstructive pulmonary disease / I. Grygus, M. Maistruk, W. Zukow // Collegium Antropologicum. - 2017. - Vol. 41 (3). - P. 255-261.

13. The quality of life in COPD patients in the process of physical rehabilitation / I. Grygus, N. Nesterchuk, W. Zukow [et al.] // Journal of Physical Education and Sport. 2019. - Vol. 19 (issue 2), Art 163. - P. 1126-1132.

14. Nici L. ATS/ERS Pulmonary Rehabilitation Writing Committee. American Thoracic Society. European Respiratory Society statement on pulmonary rehabilitation / L. Nici, C. Donner, E. Wouters [et al.] // Am. J. Respir. Crit. Care Med. - 2006. - Vol. 173, No. 12. - P. 1390-1413.

\section{REFERENCES}

1. Gryhus, I.M., \& Maistruk, M.I. (2018). Vidnovlennia fizychnoi pratsezdatnosti khvorykh na khronichne obstruktyvne zakhvoriuvannia lehen u protsesi fizychnoi reabilitatsii [Restoration of physical performance of patients with chronic obstructive pulmonary disease in the process of physical rehabilitation]. Naukovyi Chasopys NPU imeni M. P. Drahomanova: seriia 15 "Naukovo-pedahohichni problemy fizychnoi kultury (fizychna kultura i sport)" - Scientific Journal of NPU named after M.P. Drahomanov: series 15 "Scientific and pedagogical problems of physical culture (physical culture and sports)", 4 (98), 46-51 [in Ukrainian].

2. Hryhus, I.M., \& Maistruk, M.I. (2018). Zminy funktsii zovnishnoho dykhannia u khvorykh na khronichne obstruktyvne zakhvoriuvannia lehen pry zastosuvanni fizychnoi

reabilitatsii [Changes in the function of external respiration in patients with chronic obstructive pulmonary disease in the application of physical rehabilitation]. Naukovyi Chasopys NPU imeni M.P. Drahomanova: seriia 15 "Naukovo-pedahohichni problemy fizychnoi kultury (fizychna kultura i sport)" - Scientific Journal of NPU named after M.P. Drahomanov: Series 15 "Scientific and Pedagogical Problems of Physical Culture (physical culture and sports)", 1 (95), 15-19 [in Ukrainian].

3. Hrygus, I.M., Nesterchuk, N.Ye., Nohas, A.O., Prymachok, L.L., \& Zakharchenko, I.V. (2018). Vplyv provedenoi fizychnoi reabilitatsii na yakist zhyttia khvorykh na KhOZL [The influence of physical rehabilitation on the quality of life of patients with COPD]. Zdobutky klinichnoi i ekspery- 
Огляди літератури, оригінальні дослідження, погляд на проблему, випадок з практики, короткі повідомлення mentalnoi medytsyny - Achievements of Clinical and Experimental Medicine, 4, 70-74 [in Ukrainian].

4. Hryhus, I., \& Maistruk, M. (2017). Analiz fizychnoi aktyvnosti khvorykh na khronichne obstruktyvne zakhvoriuvannia lehen pry zastosuvanni fizychnoi reabilitatsii [Analysis of the physical activity of patients with chronic obstructive pulmonary disease in the application of physical rehabilitation]. Fizychna aktyvnist, zdorovia, sport Physical Activity, Health, Sports, 3 (29), 68-77 [in Ukrainian].

5. Hryhus, I., \& Maistruk, M. (2018). Zminy funktsii zovnishnoho dykhannia u khvorykh na khronichne obstruktyvne zakhvoriuvannia lehen 1 stupenia tiazhkosti u protsesi fizychnoi reabilitatsii [Changes in the function of external respiration in patients with chronic obstructive pulmonary disease 1 degree of severity in the process of physical rehabilitation]. Visnyk Prykarpatskoho universytetu. Seriia: Fizychna kultura - Bulletin of the Carpathian University. Series: Physical Education, 30, 19-27 [in Ukrainian].

6. Hryhus, I., \& Maistruk, M. (2018). Otsinka efektyvnosti fizychnoi reabilitatsii khvorykh na khronichne obstruktyvne zakhvoriuvannia lehen pomirnoho stupenia tiazhkosti [Evaluation of the effectiveness of physical rehabilitation of patients with chronic obstructive pulmonary disease of moderate severity]. Molodizhnyi naukovyi visnyk Skhidnoievropeiskoho natsionalnoho universytetu imeni Lesi Ukrainky. Fizychne vykhovannia i sport: zhurnal - Youth Scientific Bulletin of Lesya Ukrainka Eastern European National University. Physical Education and Sports: Journal, 29, 89-96 [in Ukrainian].

7. Malyavin, A.G. (2006). Respiratornaya meditsinskaya reabilitatsiya. Prakticheskoe rukovodstvo dlya vrachey [Respiratory medical rehabilitation. Practical guide for doctors]. Moscow: Prakticheskaya meditsina [in Russian].

8. Malyavin, A.G., Epifanov, V.A., \& Glazkova, I.I. (2010). Reabilitatsiya pri zabolevaniyakh organov dykhaniya [Rehabilitation for respiratory diseases]. Moscow: GEOTARMedia [in Russian].

9. Ponomarenko, G.N. (2000). Sindromno-patogeneticheskiy podkhod - strategiya razvitiya fizioterapii v KhKhl veke [Syndromic-pathogenetic approach is a strategy for the development of physiotherapy in the 21st century]. Med. reabilitatsiya, kurortologiya, fizioterapiya - Medrehabilitation, Balneology, Physiotherapy, 1 (21), 7-9 [in Russian].

10. Chuchalina, A.G. (Eds.). (2005). Standarty po diagnostike $i$ lecheniyu bolnykh KhOZL (ATS/ERS, peresmotr g. 2004) [Standards for the diagnosis and treatment of COPD patients (ATS / ERS, 2004 revision) 2004]. Moscow: Atmosfera [in Russian].

11. Ghanem, M., Elaal, E.A., Mehany, M., \& Tolba, K. (2010). Home-based pulmonary rehabilitation program: effect on exercise tolerance and quality of life in chronic obstructive pulmonary disease patients. Annals of Thoracic Medicine, 5 (1), 18-25.

12. Grygus, I., Maistruk, M., \& Zukow, W. (2017). Effect of physical therapy on respiratory function in patients with chronic obstructive pulmonary disease. Collegium Antropologicum, 41 (3), 255-261.

13. Grygus, I., Nesterchuk, N., Zukow, W., Nikolenko, O., \& Prymachok, L. (2019). The quality of life in COPD patients in the process of physical rehabilitation. Journal of Physical Education and Sport, 19 (2), 163, 1126-1132.

14. Nici, L., Donner, C., Wouters, E., Zuwallack, R., Ambrosino, N., Bourbeau, J., ..., \& Troosters, T. (2006). ATS/ERS Pulmonary Rehabilitation Writing Committee. American Thoracic Society. European Respiratory Society statement on pulmonary rehabilitation. Am. J. Respir. Crit. Care Med., 173, 12, 1390-1413.

\title{
КОНЦЕПТУАЛЬНЫЕ ОСНОВЫ ФИЗИЧЕСКОЙ РЕАБИЛИТАЦИИ БОЛЬНЫХ ХРОНИЧЕСКИМ ОБСТРУКТИВНЫМ ЗАБОЛЕВАНИЕМ ЛЕГКИХ
}

\author{
ОИ. М. Григус', П. С. Подоляка', Т. В. Гамма', И. С. Подолянчук', \\ Л. А. Заричанська', Т. В. Кучер² \\ Учебно-научный институт здравоохранения Национального университета \\ водного хозяйства и природопользования ${ }^{1}$ \\ Кременецкая областная гуманитарно-педагогическая академия имени Тараса Шевченко²
}

РЕЗЮМЕ. Хроническая обструктивная болезнь легких (ХОБЛ) на сегодня является одной из самыХ распространенных форм патологии, приводящей к высокой заболеваемости населения и смертности пациентов. Вопрос физической реабилитации больных ХОБЛ стоит на современном этапе достаточно остро. Это связано с тем, что именно у таких пациентов наблюдается наибольшее снижение приспособления организма к физической нагрузке, а эффект от лекарственной терапии может быть значительно усилен путем внедрения реабилитационных программ.

Цель - научно обосновать концептуальные основы физической реабилитации больных хронической обструктивной болезнью легких.

Результаты. Концепцию физической реабилитации больных ХОБЛ следует осуществлять с учетом ряда предпосылок: социально-педагогических, биологических и личностных. Концепция физической реабилитации больных ХОБЛ включает теоретическую составляющую, разработанную с учетом предпосылок осуществления реабилитационного процесса, к которой отнесены концептуальные подходы и основания, а также практическую составляющую в виде технологии физической реабилитации. 
Огляди літератури, оригінальні дослідження, погляд на проблему, випадок з практики, короткі повідомлення

Концепция использует концептуальные подходы: системно-исторический, системно-деятельностный, системно-функциональный, системно-целевой, системно-структурный, системно-ресурсный, системно-коммуникационный и системно-интеграционный.

В концепции все элементы, объединенные фундаментальным замыслом и ведущей идеей, представляют собой совокупность взглядов, а ее концептуальная основа - это цель, задачи, принципы и методы, которые обеспечивают понимание ее системных механизмов, алгоритм построения и функционирования. Значительное внимание уделялось особенностям сопутствующих нарушений, влияющих на общую картину физической реабилитации. Организационные основы базировались на программах физической реабилитации, учитывали все индивидуальные особенности больных.

Выводы. Предложенная целостная концепция физической реабилитации основывалась на использовании комплексного лечебного и педагогического подхода, имела индивидуальную направленность, учитывались уровень двигательных возможностей, качество жизни, физическая работоспособность больных, функциональное состояние кардиореспираторной системы, функция внешнего дыхания.

кЛючЕВЫЕ слОВА: хроническая обструктивная болезнь легких; больные; концепция; физическая реабилитация.

\title{
CONCEPTUAL BASES OF PHYSICAL REHABILITATION OF PATIENTS WITH CHRONIC OBSTRUCTIVE LUNG DISEASE
}

\author{
@I. M. Grigus', P. S. Podolyak', T. V. Gamma', I. S. Podolyanchuk', \\ L. O. Zarichanska', T. V. Kucher ${ }^{2}$ \\ Primary and Scientific Institute of Health of the National University of Water Management \\ and Use of Natural Resources ${ }^{1}$ \\ Taras Shevchenko Kremenets Regional Humanitarian and Pedagogical Academy ${ }^{2}$
}

SUMMARY. Chronic obstructive pulmonary disease (COPD) is now one of the most common forms of pathology, leading to high morbidity and mortality. The issue of physical rehabilitation of COPD patients is quite acute at the present stage. This is due to the fact that in such patients the greatest reduction in the adaptation of the body to exercise is observed, and the effect of drug therapy can be greatly enhanced by the implementation of rehabilitation programs.

The aim - to scientifically substantiate the conceptual bases of physical rehabilitation of patients with chronic obstructive pulmonary disease.

Results. The concept of physical rehabilitation of patients with COPD should be implemented taking into account a number of prerequisites: socio-pedagogical, biological and personal. The concept of physical rehabilitation of COPD patients includes a theoretical component, designed with prerequisites for the rehabilitation process, which includes conceptual approaches and bases, as well as a practical component in the form of physical rehabilitation technology.

The concept uses conceptual approaches: system-historical, system-activity, system-function, system-purpose, system-structural, system-resource, system-communication and system-integration.

In a concept, all elements that are united by a fundamental concept and a leading idea are a set of views, and its conceptual basis is the purpose, tasks, principles and methods that provide an understanding of its system mechanisms, the algorithm of construction and operation. Much attention was paid to the features of concomitant disorders that affect the overall picture of physical rehabilitation. Organizational bases were based on physical rehabilitation programs that took into account all individual characteristics of patients.

Conclusions. The proposed concept of physical rehabilitation was based on the use of complex medical and pedagogical approach, had an individual orientation, took into account the level of motor abilities, quality of life, physical performance of patients, functional state of the cardiorespiratory system, function of external respiration.

KEY WORDS: chronic obstructive pulmonary disease; patients; concept; physical rehabilitation.

Отримано 22.08.2019 